\title{
Effect of storage temperature and duration on sugar content and sensory acceptability of strawberry pulp
}

\author{
C. Bishnoi, R. K. Sharma, A. K. Godara, V. K. Sharma and S. S. Kundu \\ Department of Horticulture, CCS Haryana Agricultural University, Hisar-125004 (Haryana), INDIA \\ *Corresponding author. E-mail: chetak29@gmail.com \\ Received: February 23, 2015; Revised received: September 4, 2015; Accepted: September 21, 2015
}

\begin{abstract}
Experiment was conducted to study the effect of different treatments on preservation of strawberry pulp at ambient and low storage temperature condition. The samples were pasteurized at $100^{\circ} \mathrm{C}$ for 15 minutes $\left(T_{1}\right)$, sodium benzoate $250 \mathrm{ppm}\left(\mathrm{T}_{2}\right)$ and sodium benzoate $500 \mathrm{ppm}\left(\mathrm{T}_{3}\right)$. The respective samples were stored for two months at room $\left(25 \pm 5^{\circ} \mathrm{C}\right)$ and low $\left(7 \pm 2^{\circ} \mathrm{C}\right)$ temperature conditions and reducing sugars; total sugar and sensory evaluation were recorded at three days of interval period. The results showed that the total sugar (\%) increased in pulp sample maximum in $\mathrm{T}_{6}(5.9 \%)$ and minimum in $\mathrm{T}_{1}(4.8 \%)$, the maximum value regarding reducing sugars was recorded in $\mathrm{T}_{6}(4.9 \%)$ and minimum in $\mathrm{T}_{1}(1.4 \%)$ after $60^{\text {th }}$ days of storage. However, reducing sugars and total sugar decreased in the stored pulp at room temperature and spoiled completely on $18^{\text {th }}$ day of storage. The acceptability of organoleptic score decrease with the duration of storage in both ambient and low temperature. Among different treatments, sodium benzoate @ 500 ppm was found most effective and maintained the qualitative characteristics of preserved pulp at low $\left(7 \pm 2^{\circ} \mathrm{C}\right)$ temperature condition. In future, these experimental results may prove very useful for storage of strawberry pulp for longer duration in better quality.
\end{abstract}

Keywords: Organoleptic Rating, Pulp, Sodium Benzoate, Storage, Strawberry, Sugar

\section{INTRODUCTION}

Strawberry (Fragaria $\times$ ananassa Duch) belongs to Rosaceae, is an important fruit and is widely appreciated for its characteristic aroma, bright red color, juicy texture and sweetness. In India, the cultivated area under strawberry is nearly 15600 hectare and commercially grown in Himachal Pradesh, Maharashtra, Uttrakhand, Punjab, Haryana, Western Uttar Pradesh and Madhya Pradesh (Anonymous, 2011). Its attractive berries are soft, highly delicious and nutritious. It is an excellent source of anthocyanin and good source of vitamin $\mathrm{C}$ and have tonic, depurative, diuretic, re-mineralizing and astringent properties (Hannum, 2004).

Strawberry shows non climacteric ripening behavior. Generally, strawberry fruits are harvested early in the morning or cooler part of the day and sent to the market of the same day. The rate of ethylene evolution is low, but due to its characteristic high respiration rate $\left(50-100 \mathrm{ml} \mathrm{CO}_{2}\right.$ per $\mathrm{kg}$ of fruits per hour at $20^{\circ} \mathrm{C}$ ), it is highly perishable fruit and can be stored only for very short period (Nunes et al., 2006). During peak season, when there is a glut in the local market, the prices fall down and the crop becomes less remunerative. Being delicate, its fruits must be handled carefully, while transporting to the distant market since there are chances of deterioration of fruits during transition (Amin, 1996). These losses can be reduced by developing techniques for the preparation of different value added products either in the form of whole fruit or pulp during peak harvesting season (Durrani et al., 2010; Jain et al., 2011; Sakhale et al., 2012).

Preservation of strawberry as a whole fruit or in the form of pulp during peak harvest season and its utilization by processing industry in the later seasons could be one of the effective ways to make this crop remunerative. However, its post-harvest conservation is difficult because of its high rate of metabolic activity and great susceptibility to the attack of microorganisms. Total soluble solids and sugars in strawberry pulp increased when it was preserved by different chemical preservatives and stored at $4-15{ }^{\circ} \mathrm{C}$ for three months except in pasteurized pulp (Ayub et al., 2010; Ruiz-Nieto et al., 1997) but organoleptic rating decreased during the storage of the pulp due to change in colour, appearance and loss of taste and flavor (Hussain et al., 2011). Therefore this investigation was conducted to study the effect of storage temperature and duration on sugar content and sensory acceptability of strawberry pulp.

\section{MATERIALS AND METHODS}

The present study was conducted in the Fruit Technology Laboratory of Department of Horticulture, Chaudhary Charan Singh Haryana Agricultural University, Hisar during 2011 to 2012 season. The strawberry cultivar 'Ofra' was selected for the present 
Table 1. Total sugar (\%) of strawberry pulp during storage as affected by various treatments.

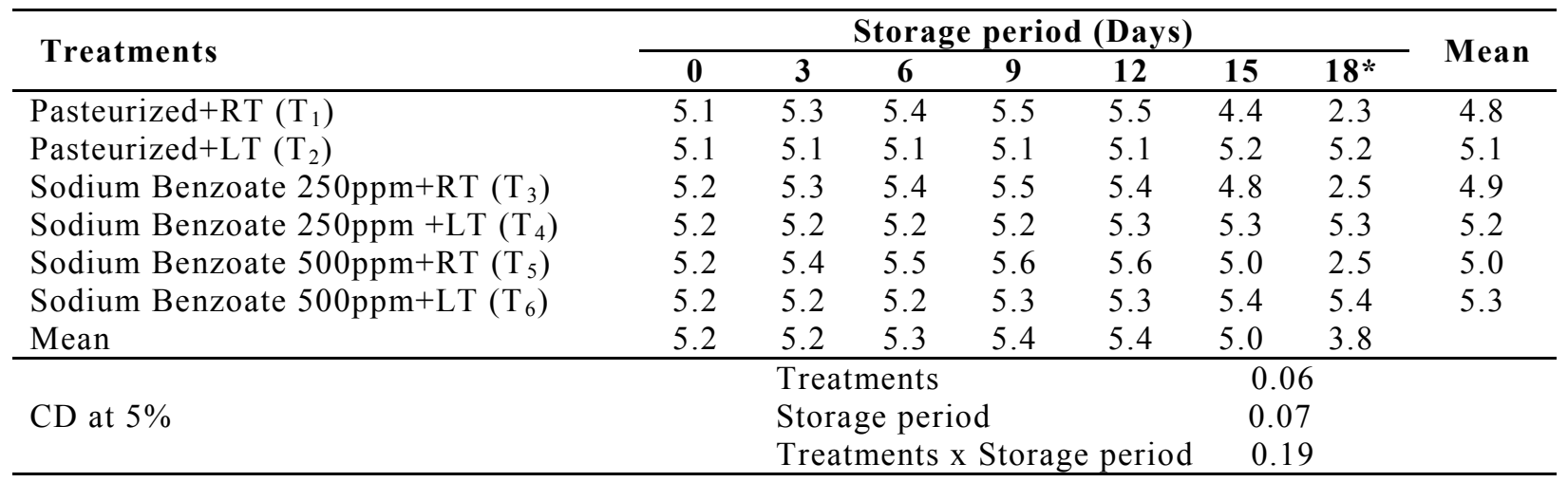

*Pulp stored at room temperature T1, T3 and T5 got spoiled after 18 days of storage.

Table 2. The total sugar (\%) of strawberry pulp during storage as affected by various treatments.

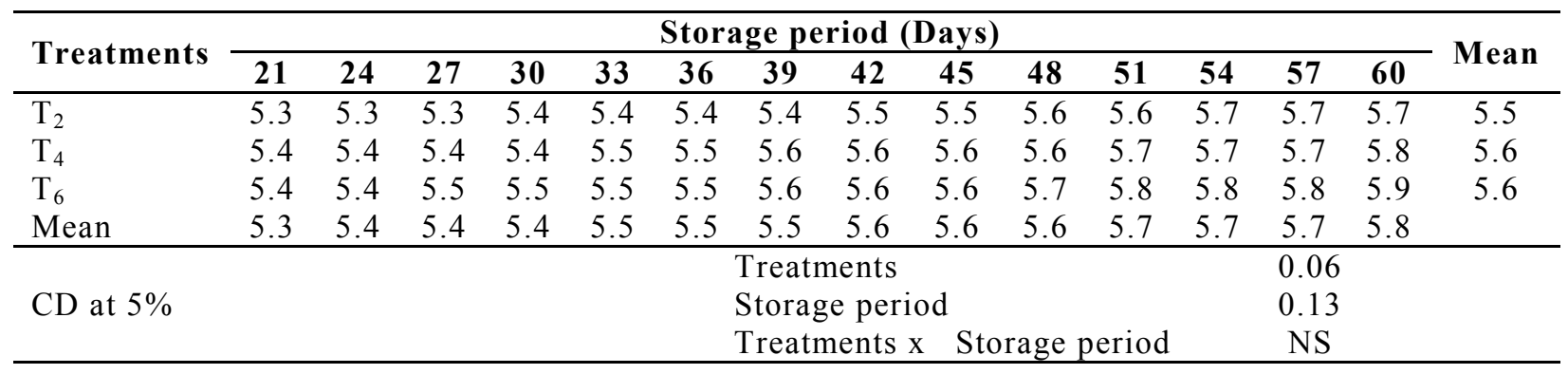

Table 3. The reducing sugars (\%) of strawberry pulp during storage as affected by various treatments

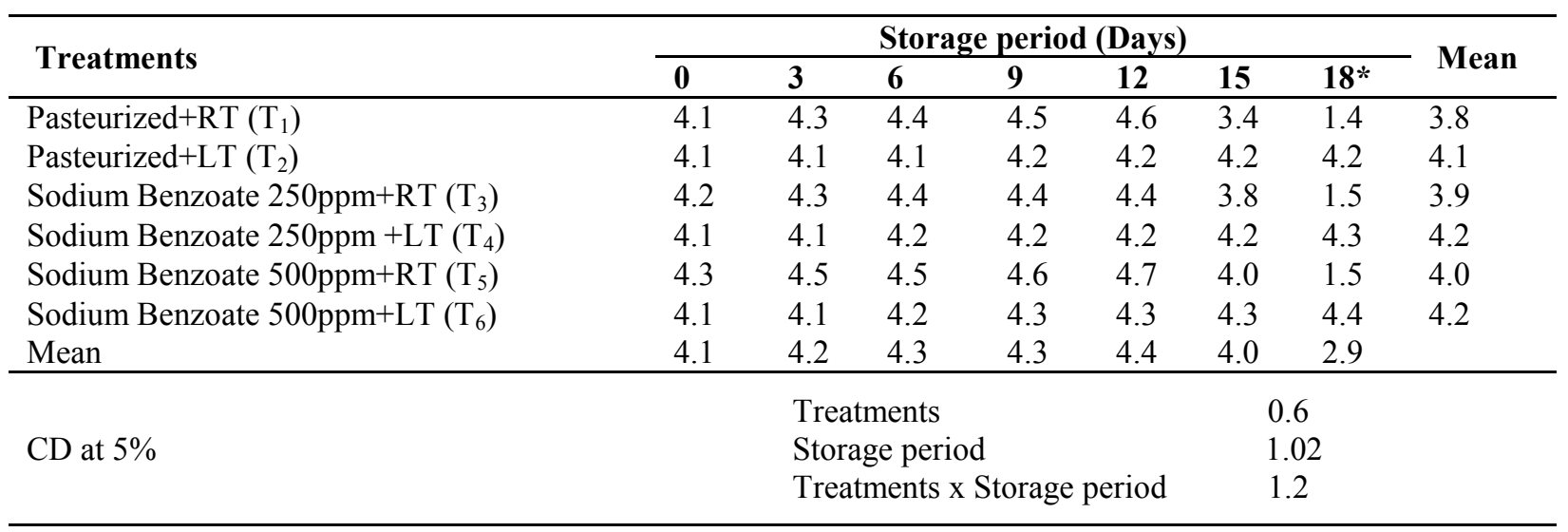

* Pulp stored at room temperature T1, T3 and T5 got spoiled after 18 days of storage.

investigation. Uniform red colour, medium size disease free strawberry (cv. Ofra) fruits were selected for the preparation of pulp. The sepals were removed manually and the fruits were crushed with the help of PulpHomogenizer mixture. The total pulp was divided into three lots. The pulp of first lot was packed in sterilized glass bottles of size $450 \mathrm{~g}$ and was pasteurized at $100^{\circ}$ $\mathrm{C}$ temperature for 15 minutes. The pulp of second and third lots were treated with sodium benzoate@250 and $500 \mathrm{ppm}$, respectively and then packed in sterilized glass bottles of $450 \mathrm{~g}$. The filled jars of each lot were divided into two sub-groups and stored at ambient room $\left(25 \pm 5^{\circ} \mathrm{C}\right)$ and low $\left(7 \pm 2^{\circ} \mathrm{C}\right)$ temperature, respectively. Estimation of total, reducing sugars and evaluation of sensory parameters were carried out at three days of interval with four replications by using the method of Hulme and Narain (1993). The stored pulp was subjected to sensory evaluation by a panel of six judges following the 9 points Hedonic rating scale. The frozen fruits were evaluated for color, flavor, appearance, and texture. Characters with mean scores of 6 or more out of 9 marks were considered acceptable. The data were analyzed according to the procedure for analysis of completely randomized design (CRD) as given by Panse and Sukhtme (1984). The overall significance of difference among the treatments was tested, using critical differences (C.D.) at 5\% level of significance. The results were statistically analyzed with the help of a windows based computer package OPSTAT (Sheoran, 2004). 
Table 4. Reducing sugars (\%) of strawberry pulp during storage as affected by various treatments.

\begin{tabular}{|c|c|c|c|c|c|c|c|c|c|c|c|c|c|c|c|}
\hline \multirow{2}{*}{ Treatments } & \multicolumn{14}{|c|}{ Storage period (Days) } & \multirow{2}{*}{ Mean } \\
\hline & 21 & 24 & 27 & 30 & 33 & 36 & 39 & 42 & 45 & 48 & 51 & 54 & 57 & 60 & \\
\hline $\mathrm{T}_{2}$ & 4.3 & 4.3 & 4.3 & 4.4 & 4.4 & 4.4 & 4.4 & 4.5 & 4.5 & 4.6 & 4.6 & 4.7 & 4.7 & 4.7 & 4.5 \\
\hline $\mathrm{T}_{4}$ & 4.4 & 4.4 & 4.4 & 4.4 & 4.5 & 4.5 & 4.6 & 4.6 & 4.6 & 4.6 & 4.7 & 4.7 & 4.8 & 4.8 & 4.6 \\
\hline $\mathrm{T}_{6}$ & 4.4 & 4.4 & 4.5 & 4.5 & 4.5 & 4.5 & 4.6 & 4.6 & 4.6 & 4.7 & 4.8 & 4.8 & 4.9 & 4.9 & 4.6 \\
\hline Mean & 4.3 & 4.4 & 4.4 & 4.4 & 4.4 & 4.5 & 4.5 & 4.6 & 4.6 & 4.6 & 4.7 & 4.7 & 4.8 & 4.8 & \\
\hline $\mathrm{CD}$ at $5 \%$ & & & $\begin{array}{l}\text { atm } \\
\text { rage } \\
\text { eatm }\end{array}$ & $\begin{array}{l}\text { hts } \\
\text { perio } \\
\text { ats } x\end{array}$ & tora & per & & & $\begin{array}{l}0 . \\
0 . \\
\mathrm{N}\end{array}$ & & & & & & \\
\hline
\end{tabular}

Table 5. The overall acceptability of organoleptic scores (out of 9) of strawberry pulp during storage as affected by various treatments.

\begin{tabular}{|c|c|c|c|c|c|c|c|c|}
\hline \multirow{2}{*}{ Treatments } & \multicolumn{7}{|c|}{ Storage period (Days) } & \multirow{2}{*}{ Mean } \\
\hline & $\mathbf{0}$ & 3 & 6 & 9 & 12 & 15 & $18 *$ & \\
\hline Pasteurized+RT $\left(\mathrm{T}_{1}\right)$ & 8.37 & 7.93 & 6.61 & 5.55 & 4.13 & 2.32 & 1.64 & 5.22 \\
\hline Pasteurized $+\mathrm{LT}\left(\mathrm{T}_{2}\right)$ & 8.37 & 8.37 & 8.30 & 8.23 & 8.08 & 8.03 & 7.95 & 8.19 \\
\hline Sodium Benzoate $250 \mathrm{ppm}+\mathrm{RT}\left(\mathrm{T}_{3}\right)$ & 8.45 & 8.11 & 7.48 & 6.74 & 4.48 & 2.32 & 1.43 & 5.57 \\
\hline Sodium Benzoate $250 \mathrm{ppm}+\mathrm{LT}\left(\mathrm{T}_{4}\right)$ & 8.45 & 8.45 & 8.33 & 8.27 & 8.23 & 8.15 & 8.10 & 8.28 \\
\hline Sodium Benzoate $500 \mathrm{ppm}+\mathrm{RT}\left(\mathrm{T}_{5}\right)$ & 8.45 & 8.19 & 7.77 & 6.52 & 5.32 & 3.06 & 1.96 & 5.90 \\
\hline Sodium Benzoate 500ppm+LT $\left(\mathrm{T}_{6}\right)$ & 8.45 & 8.45 & 8.39 & 8.37 & 8.35 & 8.35 & 8.30 & 8.38 \\
\hline Mean & 8.42 & 8.25 & 7.81 & 7.28 & 6.43 & 5.37 & 4.90 & \\
\hline \multirow{3}{*}{$\mathrm{CD}$ at $5 \%$} & \multicolumn{4}{|c|}{ Treatments } & \multicolumn{3}{|c|}{0.11} & \\
\hline & \multicolumn{4}{|c|}{ Storage period (Days) } & \multicolumn{3}{|c|}{0.12} & \\
\hline & \multicolumn{4}{|c|}{ Treatments x Storage period } & & & & \\
\hline
\end{tabular}

* Pulp stored at room temperature T1, T3 and T5 got spoiled after 18 days of storage.

Table 6. The overall acceptability of organoleptic scores (out of 9) of strawberry pulp during storage as affected by various treatments.

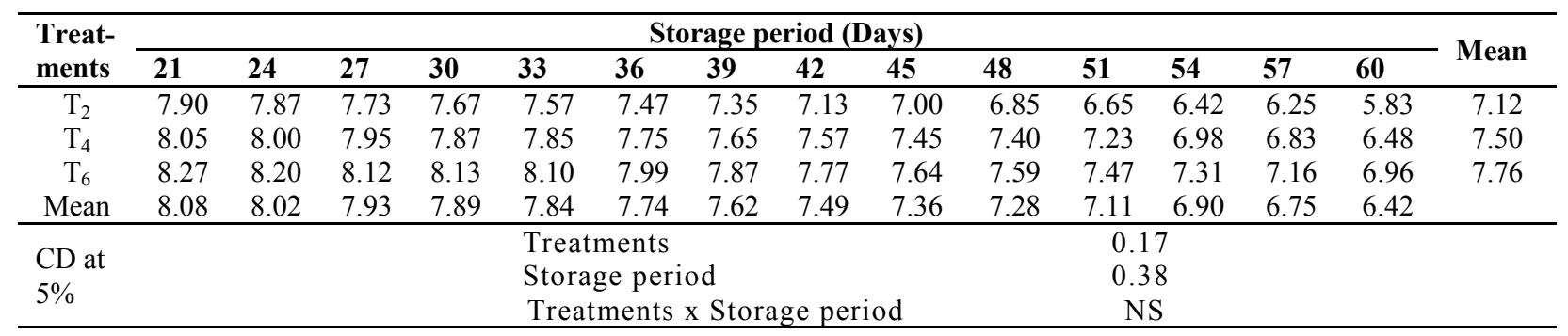

\section{RESULTS AND DISCUSSION}

The data of total sugar of strawberry pulp during storage up to 18 days have been presented in Table 1 and during later storage period in Table 2. Average maximum total sugar was found in $\mathrm{T}_{6}(5.3 \%)$ which was significantly higher among all the treatments and minimum in $\mathrm{T}_{1}(4.8 \%)$ after $18^{\text {th }}$ day of storage (Table 1) and after later storage period it was found maximum $(5.6 \%)$ in $\mathrm{T}_{6}$ and $\mathrm{T}_{4}$. The average total sugar of strawberry pulp was increased up to 12 days of storage and then decreased drastically after 12 to 18 days of storage. The maximum total sugar was found in $\mathrm{T}_{6}$ (5.4\%) which is at par with $\mathrm{T}_{4}$ and minimum in $\mathrm{T}_{1}$ $(2.3 \%)$ after 18 days of storage. However, the pulp treated with different treatment and stored at low temperature, total sugar was increased with the increase in storage period and found maximum $(5.8 \%)$ after $60^{\text {th }}$ days of storage. Sodium benzoate @ 500 ppm and 250 ppm was found most effective in maintaining the total sugar of the pulp at low temperature. In the present study, total sugar increased continuously with the increase in storage period upto $9^{\text {th }}$ days of storage and after that, it decreased at room temperature (Table 1). It indicated that the insoluble cell wall material was converted into soluble material at faster rate and completed the reactions in 9 days. Strawberry pulp stored at low temperature did not show any significant variation among the treatments and highest total sugar was recorded in the pulp treated with sodium benzoate (a) 500 ppm Table 2. The increase in total sugar content during storage could be due to conversion of insoluble cell wall materials into soluble materials or the conversion of organic acid into sugars. These results are in agreement with Ruiz-Nieto et al. (1997) who showed an increase in sugar content in strawberry fruits during storage period.

The data pertaining to effect of treatments on reducing sugars of strawberry pulp during storage up to 18 days have been presented in Table 3 and during later storage 
period in Table 4. Average reducing sugars of strawberry pulp differed significantly in all the treatments except in treatments $\mathrm{T}_{4}$ and $\mathrm{T}_{6}$ and recorded maximum in $\mathrm{T}_{4}, \mathrm{~T}_{6}(4.2 \%)$ and minimum in $\mathrm{T}_{1}(3.8 \%)$ after 18 days of storage up to $18^{\text {th }}$ day of storage (Table 3) and after later storage period the maximum reducing sugars $(4.6 \%)$ was recorded in $\mathrm{T}_{6}$ and $\mathrm{T}_{4}$ which was significantly higher than $\mathrm{T}_{2}$. Average reducing sugars of strawberry pulp was increased up to 12 days of storage and then sharply decreased up to $18^{\text {th }}$ day of storage. The maximum reducing sugars was found in $\mathrm{T}_{6}(4.4 \%)$ and minimum in $\mathrm{T}_{1}(1.4 \%)$ after 18 days of storage. However, the pulp treated with different treatments and stored at low temperature, the reducing sugars increased with the increase in storage period and was found maximum $(4.8 \%)$ at the end of storage period. The methods along with days of storage had no effect on reducing sugars at low temperature. Reducing sugars increased continuously with the increase in storage period except between $9^{\text {th }}$ to $18^{\text {th }}$ days of storage at room temperature and no significant variation was found in strawberry pulp stored at low temperature. Highest reducing sugars were recorded in the pulp treated with sodium benzoate@ 500 ppm (Table $3 \& 4$ ). Increase in reducing sugars content in the pulp during storage might be due to inversion of non-reducing to reducing sugars (Ranote and Bains, 1982). These results are in agreement with the results of Ayub et al. (2010), who suggested that sucrose content of the pulp might get converted to glucose and fructose during storage, thereby resulting in the change in reducing sugars of pulp.

The changes in organoleptic score for overall acceptability of strawberry pulp during storage up to 18 days have been presented in Table 5 and during later storage period in Table 6. Average organoleptic score (8.38) was highest in treatments $\mathrm{T}_{6}$ followed by $\mathrm{T}_{4}(8.28 \%)$ up to $18^{\text {th }}$ day of storage (Table 5) and after $18^{\text {th }}$ day of storage, the highest score $(7.76 \%)$ was recorded in treatment $\mathrm{T}_{6}$ which was significantly higher than $\mathrm{T}_{4}$ and $T_{2}$. Throughout the storage period, the organoleptic score decreased with increase in storage period. Average organoleptic score decreased significantly up to 18th day of storage after that it decreased nonsignificantly till the end of storage period. The treatment $\mathrm{T}_{6}$ obtained highest organoleptic scores (7.76) and found most effective for preparing the products even after $60^{\text {th }}$ days after storage at low temperature. In the present study, highest average organoleptic score (7.76 and 7.50) was recorded in the pulp treated with (a) 500 and 250 ppm sodium benzoate respectively on 60 days of storage at low temperature. However, the pulp stored at room temperature was rated low and the pulp got spoiled on $9^{\text {th }}$ day of storage (Table 5). Organoleptic rating decreased due to changes in color, appearance, aroma, texture and overall acceptability of stored pulp. These findings are in line with Hussain et al. (2011) from apple and apricot blend juice preserved with sodium benzoate at refrigeration temperature, who showed that acceptability of the juice decreased with storage period. The loss of flavor and taste might be due to the degradation of ascorbic acid and furfural production as indicated by Perez and Sanz ( 2001).

\section{Conclusion}

The total sugar and reducing sugars of strawberry pulp increased up to 12 days of storage and then decreased drastically after 12 to 18 days of storage. However, for the pulp treated with different treatments and stored at low temperature, total sugar and reducing sugars were increased with the increase in storage period and found maximum $5.8 \%$ and $4.6 \%$ respectively, after $60^{\text {th }}$ days of storage. Sodium benzoate@500 ppm was found most effective in maintaining the total sugar and reducing sugars of the pulp stored at low temperature. The pulp stored at low temperature after treated with 500 ppm, and $250 \mathrm{ppm}$ was having better organoleptic ratings and were found suitable for further utilization even after 60 days of storage at low temperature. However, the pulp stored at room temperature was rated low and the pulp got spoiled by 9th day of storage. The pulp treated with sodium benzoate @ 500 ppm stored at low temperature obtained highest organoleptic scores (7.76) and was found most effective for preparing the products even after $60^{\text {th }}$ days after storage.

\section{REFERENCES}

Amin, N.U., (1996). Evaluation of different strawberry cultivars for off Season production under plastic tunnel. M.Sc. (Hon's) Thesis, Department of Horticulture, NWFP Agricultural University, Peshawar, Pakistan.

Anonymous (2011). Trends in non-traditional fruits in India. The Tribune, XXI, Chandigarh.

Ayub, M., Javid, U., Ali, M. and Alam, Z. (2010). Evaluation of strawberry juice preserved with chemical preservatives at refrigeration temperature. International Journal of Nutrition and Metabolism, 2(2): 27-32.

Durrani, Y., Ayub, M., Muhammad, A. and Asad, A. (2010). Physicochemical response of apple pulp to chemical preservatives and antioxidant during storage. International Journal of Food Safety, 12: 20-28.

Hannum, S. M. (2004). Potential impact of strawberries on human health. Crit. Rev. Food Sci., 44: 1-17.

Hulme, A.C. and Narain, R. (1993). The ferrycynide method for determination of reducing sugars. A modification of Hegedom-Jenson Hanes Technique. Biochemistry Journal, 25: 1051-1061.

Hussain, I., Alam, Z. and Muhammad, A. (2011). Evaluation of apple and apricot blend juice preserved with sodium benzoate at refrigeration temperature. World Journal of Dairy and Food Science, 6(1): 79-85.

Jain, P.K., Jain, P. and Nema, P. K. (2011). Quality of guava and papaya fruit pulp as influenced by blending ratio and storage period.American J. Food Technology, 6 (6):507.

Nunes, M.C.N., Brecht, J.C., Morais, A.M. and Sargent, S. A. (2006). Physiochemical changes during strawberry 
development in the field compared with those that occur in harvested fruits during storage. J. Sci. Food and Agric., 1: 180-190.

Panse, V.G. and Sukatme, P.V. (1967). Statistical methods for Agricultural workers. Indian Council of Agricultural Research, New Delhi, pp. 155.

Perez, A.G. and Sanz, C. (2001). Effect of high oxygen and high carbon-dioxide atmospheres on strawberry flavor and other quality traits. Journal of Agriculture and Food Chemistry, 49: 2921-2930.

Ranote, P.S. and Bains, G.S. (1982). Juice of kinnow. Indian Food Packer, 36(5): 23-33.

Ruiz-Nieto A., Lopez, A.J.M., Lopez, M.R., Lopez, M.J.,
Medina, J.J., Scheer, H.A.T., Lieten, F. and Dijkstra, J. (1997). Analysis of sucrose's from strawberry cultivars of commercial interest contents evolution. Proceedings of the third international strawberry symposium, Veldhoven, Netherlands. Acta Horticulturae, 439: 663667.

Sakhale, B.K., Pawar, V.N. and Ranveer, R.C. (2012). Studies on effect of chemical preservative on keeping quality of Kesar mango pulp. Open Access Scientific Reports. 1(3). http://dx.doi.org/ 10.4172/ scientificreports. 184 .

Sheoran, O.P. (2004). Statistical package for Agricultural Research workers, CCS HAU, Hisar.http://hau.ernet.in. 